\title{
Comparative Study of Urinary Albumin Excretion in Pre-Eclamptic Women in Different Duration
}

\begin{abstract}
Pre-eclampsia is one of the important causes of maternal death in developing countries like Bangladesh. The analysis of 24 hour urine for protein excretion remains the best method of monitoring proteinuria in pregnancy. 24 hour urine collection is notoriously difficult to obtain when repeated analysis is needed in pre-eclamptic women. With this back ground, this study was carried out in BSMMU and DMCH from November 2004 to January 2005 to determine whether 12 hours urine collection
\end{abstract}

\section{Introduction}

Hypertension complicates at least 5-8 percent of all pregnancies. ${ }^{1}$ Among the hypertensive disorders of pregnancy the highest risks are associated with pre-eclampsia and eclampsia. ${ }^{2}$ Pre-eclampsia is an important cause of both perinatal and maternal morbidity and mortality. ${ }^{3}$ Hypertension is a sign of an underlying pathology which may be pre-existing or appears for the first time during pregnancy. ${ }^{4}$ Clinically, pre-eclampsia is characterized by the onset of hypertension, proteinuria and oedema usually beginning in the third trimester. ${ }^{5}$

A small amount of protein 200-300 mg/24 hour is normally excreted in the urine and this amount are probably not increased in pregnancy. ${ }^{6}$ A loss of $>300$ $\mathrm{mg} / 24$ hour suggest a disease process. ${ }^{7}$ Proteinuria is a late feature but is an important sign of preeclampsia and detecting proteinuria is an integral part of the management of hypertensive pregnant women. The presence of proteinuria is required for the diagnosis of pre-eclampsia ${ }^{8.9}$ and is associated with a higher rate of maternal and foetal complica tion among hypertensive pregnancies. ${ }^{10,11}$ Similarly chronic hypertension with superimposed preeclampsia is associated with a higher risk than is stable chronic hypertension during pregnancy. ${ }^{12}$ Proteinuria is extremely valuable as a prognostic sign in preeclampsia. Frequent monitoring of the amount of protein excreted in the urine must be a part of the evaluation of these patients. A significant increase in proteinuria indicates that the disease has worsened. ${ }^{13}$ Weekly estimation of 24 hours protein excretion is the part of management of preeclampsia in inpatient care. ${ }^{14}$ The collection of urine over 24 hours how ever is inconvenient, time consuming and errors due to incomplete collections 1. Dr. Nusrat Ara Yousuf, Jr Consultant of Obstetrics \& Gynecology.
UHC Sulla Sunamgonj.

2. Dr. M. Anwar Hussain ,Professor Head of the department of Obstetrics \& Gynecology. BSMMU.

3. Dr. Khadija Begum, H M O in the department of Obstetrics \& Gynecology,BSMMU.

\section{Corresponding author}

Dr. Nusrat Ara Yousuf, Jr Consultant of Obstetrics \& Gynecology, UHC Sulla,Sunamgonj.

\begin{abstract}
for measuring albumin excretion in pre-eclamptic women can be a substitute for 24 hour collection. This study was performed on 40 women with pre-eclampsia who were admitted to the hospital. In each patient urinary albumin concentrations in two 12 hours samples (12 hour day and 12 hours night samples) were measured against the standard 24-hour albumin excretion. It was found that albumin concentrations in the 12-hour day and 12-hours night collections were close to the concentrations of the 24-hour collection.
\end{abstract}

and spillage are common. Moreover it is difficult waiting 24 or more hours to know whether proteinuria is truly present. ${ }^{15}$ Several authors have advocated shortened timed clearances to alleviate the problems of 24 hours urine collection. Brodows et al. ${ }^{16}$ Recommended 3 hours collections. Cook. ${ }^{17}$ used overnight collection and Sochett and Odnoman. ${ }^{18}$ found 1-hour timed collections satisfactory. This shorter timed urine collection for detecting proteinuria can be tried in pre-eclamptic women. However for pregnant women, particularly during continuous bed rest in hospital the circadian variation in albumin excretion is smaller or absent and it may therefore be possible to use shorter collection period. ${ }^{19}$ A recent study was performed by Helle Kieler with thirty women of preclampsia in Uppsala University Hospital, Sweden, on 2003. He showed that the gold standard of 24 hours urinary excretion for assessment of albuminurea in pre-eclamptic women can be substituted with a 12 hours collections. ${ }^{20}$ It will be a great advantage if reliable measurement of protein excretion could be obtained from a shorter collection period. The most commonly used screening tests for detecting proteinuria is the 'stix' test. It is particularly sensitive for albumin, but has a low sensitivity for other proteins such as globulin and Benzones protein. ${ }^{21}$ According to KUO et al. ipstick urine analysis cannot be relied on either to detect or to exclude the presence of proteinuria in pregnant women. ${ }^{22}$ It has been found that the albumin excretion in urine correlates significantly to the albumin/creatinine ratio during pregnancy. ${ }^{23}$

\section{Materials and method}

This prospective study was carried out in the Department of Obstetric and Gynaecology, Bangabandhu Sheikh Mujib Medical University, and Dhaka Medical College Hospital, during the period of 01.11 .04 to 28.02.05.Among the admitted patient total 40 pregnant women with pre-eclampsia was taken with proper selection criteria. The criteria for inclusion were hypertension $(140 / 90 \mathrm{mmHg}$ or more) after 20th week of gestation and a bed side urine albumin positive. Detailed medical and obstetric history was taken and thorough examination was done and all the information's were recorded in the pre-designed data 
collection sheet. Before collection of urine all women were carefully instructed about the study and an informed verbal consent was taken. Two clean, dry and graduated plastic containers with $10 \mathrm{ml}$ of toluine as preservatives in each were given to the patient for collection of urine. In one container urine was collected from 8.00 am to 8.00 pm which was called 12 hours day collection. In another container urine was collected from $8.00 \mathrm{pm}$ to the next day 8.00 am which was called 12 hours night collection. 5 $\mathrm{ml}$ of urine from 12 hours day and $5 \mathrm{ml}$ of urine from 12 hours night collections were taken in two dry, clean test tube which was called 12 hours day and night urine samples respectively. Then the urine in the day and night containers were mixed to form a 24 hour urine collection. $5 \mathrm{ml}$ of urine from mixed collection was taken in test tube no.-3 which was called 24 hours urine sample. Three urine samples in three test tubes (test tube no.- $1=12$ hours day sample, test tube no. $-2=12$ hours night sample and test tube no.-3 $=24$ hours urine samples) were sent to the Biochemistry laboratory of BSMMU for analysis of proteinuria. Mean and median value of each of the urine samples was measured and median differences were calculated. Median difference between 24 hour urinary albumin and 12 hours day and night sample were calculated.

\section{Results}

Table-I: Age distribution of patients.

\begin{tabular}{|ccc|}
\hline Age group (in years) & Total No. of patient $\mathbf{n}=\mathbf{4 0}$ & $\begin{array}{c}\text { Percentage } \\
(\%)\end{array}$ \\
$16-20$ & 10 & 25 \\
$21-25$ & 12 & 30 \\
$26-30$ & 11 & 27 \\
$31-35$ & 6 & 15 \\
3640 & 1 & 2 \\
\hline
\end{tabular}

Table-II: Socio-economic status.

\begin{tabular}{|lcc|}
\hline \multicolumn{1}{|l}{ Socio-economic status } & Number of patient & Percentage \\
$\mathrm{n}=40$ & & $(\%)$ \\
Lower & & 50 \\
Middle & 15 & 37.5 \\
Upper & 5 & 12.5 \\
\hline
\end{tabular}

Table-III: Distribution of parity.

\begin{tabular}{|ccc|}
\hline Parity & $\begin{array}{c}\text { No. of patient } \\
\mathrm{n}=40\end{array}$ & $\begin{array}{c}\text { Percentage } \\
(\%)\end{array}$ \\
Prime & 26 & 65 \\
$1-3$ & 10 & 25 \\
$>3$ & 4 & 10 \\
\hline
\end{tabular}

Table-IV: Distribution of patients upon aking antihypertensive drug.

\begin{tabular}{|lcc|}
\hline Have taken & No. of patient & Percentage \\
antihypertensive & $\mathrm{n}=40$ & $(\%)$ \\
Yes & 38 & 95 \\
No & 2 & 5 \\
\hline
\end{tabular}

Table-V: Distribution of the patients having family history of hypertension/pre-eclampsia.

\begin{tabular}{|lcc|}
\hline Family history & No. of patient & Percentage \\
& $\mathrm{n}=40$ & $(\%)$ \\
Hypertension & 11 & 27.5 \\
Preeclampsia & 4 & 10 \\
No comments & 25 & 62.5 \\
\hline
\end{tabular}

Table-VI: Gestational age at the time of admission

\begin{tabular}{|lcc|}
\hline Gestational age & No. of patient & Percentage \\
& $\mathrm{n}=40$ & $(\%)$ \\
$22-28$ & 10 & 25 \\
$29-35$ & 25 & 62.5 \\
36 or more & 5 & 12.5 \\
\hline
\end{tabular}


Table-VI: Gestational age at the time of admission

\begin{tabular}{|lcc|}
\hline Gestational age & No. of patient & Percentage \\
$22-28$ & $\mathrm{n}=40$ & $(\%)$ \\
$29-35$ & 10 & 25 \\
36 or more & 25 & 62.5 \\
\hline
\end{tabular}

Table-VII: Weight gain during pregnancy.

\begin{tabular}{|ccc|}
\hline B.Pin earlypregnancy in & \multicolumn{2}{c|}{ No. of patient } \\
$\mathrm{mmHg}$ & & $\mathrm{n}=40$ \\
& Mean & SD \\
& & \\
Systolic & 112.75 & 13.20 \\
Diastolic & 70.63 & 10.20 \\
\hline
\end{tabular}

Table-IX: Distribution of B.P at the time of admission

B.Pon admission in No. of patientn=40 Percentage $(\%)$ $\mathrm{mmHg}$

\begin{tabular}{lcc} 
& Mean & SD \\
Systolic & 166.38 & 20.38 \\
Diastolic & 102.88 & 9.93 \\
\hline
\end{tabular}

Table-X: Distribution of urinary albumin concentration in three samples.

\begin{tabular}{ccc|}
$\begin{array}{c}\text { Number of patients } \\
(\mathrm{n}=40)\end{array}$ & Mean \pm SD mg/L & Median mg/L \\
A & $1744.90 \pm 513.26$ & 1635 \\
B & $1768.35+510.08$ & 1689 \\
C & $1757.63 \pm 549.92$ & 1640 \\
\hline
\end{tabular}

Table-XI: Median difference of albumin concentration

\begin{tabular}{|cc|}
$\begin{array}{c}\text { in three samples. } \\
\text { Number of patient }\end{array}$ & $\mathrm{n}=40$ \\
C-A & $10 \mathrm{mg} / \mathrm{L}$ \\
C-B & $-7.5 \mathrm{mg} / \mathrm{L}$ \\
A-B & $-20 \mathrm{mg} / \mathrm{L}$ \\
\hline
\end{tabular}

Table-XII: Comparison of urinary albumin excretion in the different samples.

\begin{tabular}{|cc|}
\hline Number of patient $\mathrm{n}=40$ & P Value $^{3}$ \\
Group A vs. B & $>0.10^{\mathrm{ns}}$ \\
Group A vs. C & $>0.50^{\mathrm{ns}}$ \\
Group B vs. C & $>0.50^{\mathrm{ns}}$ \\
\hline
\end{tabular}

\section{Discussion}

Pre-eclampsia is a serious complication of pregnancy and are responsible for significant morbidity and mortality in the foetus, the newborn infant and mother. It is important to detect the condition as early as possible. Albuminuria is an important sign of pre-eclampsia and repeated urine analysis to screen for the condition are part of the standard antenatal care; detecting proteinuria in pregnant women is usually done by routine visual dipstick urinalysis. However recent studies have documented inaccuracies of this method, giving high false positive and false negative results, when compared with the gold standard of 24 hour urine measurement. When pre-eclampsia with persistent albuminuria develops, urinary albumin excretion is monitored by frequent 24 hour urine samples. The purpose of this surveillance was that increased albumin excretion is a sign of aggravation of pre-eclampsia and reflects serious nephropathy; massive albumin excretion may result in planned preterm delivery. Obtaining a complete 24 hour Urine collection is difficult, is inconvenient, time consuming and errors due to incomplete collections and spillage are common. In the present study, we have tried to overcome the difficulties of 24 hour urine collection by a shorter collection period. In this study, in women with pre-eclampsia who had significant albuminuria, we found good agreement between urinary albumin concentrations measured in samples collected for 12 hours and the traditional 24 hours collection. This is in accordance with the observation made by the Dr. Helle Kieler et al in a prospective study in the Department of women's and children's health, Obstetric and Gynaecology, Uppsala University Hospital, Sweden, measured urinary albumin excretion in 30 women with pre-eclampsia. He concluded that the gold standard of 24-hour urinary excretion for assessment of albuminuria in pre-eclamptic women could be substituted with a 12-hour collection. He also observed that spot urine samples were inaccurate and is therefore not recommended for quantification of albumin excretion. He showed that the median difference between the 24 hour and 12 hour day urinary albumin excretion was $-3 \mathrm{mg} / \mathrm{L}$ which was $10 \mathrm{mg} / \mathrm{L}$, in our study and the median differ ence between the 24 hour and 12 hours night urinary albumin excretion was $17 \mathrm{mg} / \mathrm{L}$ which was -7.5 $\mathrm{mg} / \mathrm{L}$ in our study. Our study showed that the agreement between albu min concentration in 24 hour and 12 hour night sample was slightly better than that of the 12 hour day sample $(-5.7 \mathrm{mg} / \mathrm{L}$ vs. $10 \mathrm{mg} / \mathrm{L})(17 \mathrm{mg} / \mathrm{L}$ vs. $-3 \mathrm{mg} / \mathrm{L}$ in previous study). 
Median difference in night sample over estimate the albumin concentration as indicated by the negative values for mean and median differences. Over estimation of albumin excretion may lead to interventions such as planned preterm delivery to be performed earlier than required. Under estimation of albumin excretion however, may delay detection of severe nephropathy resulting in damage to the kidney. Urinary albumin excretion is at least in diabetic patients known to have day to day variability; presumably, the same is true in pre-eclampsia. However, there is little likelihood that this biologic variability influences the results as all samples were collected within 24 hours period. In some studies urinary albumin/creatinine ratio is a valid estimate of albumin excretion rate. But other studies found that adding analysis of creatinine is of limited use and only increases the costs. As the increase in albumin excretion in severe pre-eclampsia, occurs rapidly and suddenly, frequent urine analysis are required. This analysis should be valid and easy to perform and should be as inexpensive as possible; a night sample collection starting at $8.00 \mathrm{pm}$ and ending at $8.00 \mathrm{am}$ is thought to be acceptable to women then a 24 hour collection. A shorter period should reduce the risk of incomplete collection.

\section{Conclusion}

In the present study we have observed that the difference between the urinary albumin excretion in 24 hour sample and 12 hour day and 12 hour night sample was statistically insignificant. This finding suggested that the 24-hour urinary excretion for assessment of albuminuria in pre-eclamptic women may be substituted with a 12-hour collection. Further study with a large number of patients is necessary to determine whether 12-hour urinary albumin excretion can be used for quantification of albuminuria in pre-eclamptic women.

\section{References}

1. Hoque MM, Bulul T, Mahal M, Islam NAF and Ferdousi M, Serum Homocysteine in pre-eclampsia \& eclampsia, Bangladesh Medical Research Council Bulletine, 2008,34: 16-20.

2. Decherney AH, Nathan L, Goodwin TM, Laufer N. Current Diagnosis \& Treatment - obstetrics and Gynaecology. Hypertension in pregnancy, 10 th edition. M C Graw Hill, P- 318- 326.

3. Taufield P.A., Ales K.L., Resnick L.M., Druzin M.L., Gertner, J.M. and Laragh J.H: Hypocalciuria in pre-eclampsia. N Engl J Med, 1987; 316:715-8.

4. Dutta D.C: Editor Textbook of obstetrics including perinatology and contraceptions, 6th edition, New central book agency (p) Ltd. India, 2005; p-221.

5. Paternoster DM, Fantinato S, Manganelli F, Nicolini U, Milani M, Ginolami A: Recent progress in the therapeutic management of pre-eclampsia. Expert opin. Pharmacother. 2004 Nov; (11): 2233-9.

6. Wright A, Stule P, Bennet J.R. Watts G and Plak A, 1987. Urinary excretion of albumin in normal pregnancy. Br J obstet Gynecol 94, 408 - 412.

7. Alan H, Dech erncy, Md. Editor. Current obstetrics and gynaecologic diagnosis and treatment, 9th edition. A large medical book, P - 338 .

8. Davey DA, MacGillivray I, Classification and defini tion of the hypertensive disorders of pregnancy. Am J obstet Gynecol 1988; 158: 892-898.

9. National high blood pressure education program working group. Report on high blood pressure in pregnancy. Am J obstet gynecol 1990; 163: 1691- 1712.

10. Ferrazanis, Caruso A, D'c carolis S, Martino IV, Mancuso S, Proteinuria and outcome of 444 pregnancies complicated by hypertension. Am J Obstet gynecol 1990; 162: 366- 371.

11. Brown Ma, Buddie ML. Importance of non-proteinuric hypertension in pregnancy. Hypertens pregnancy, 1995; 14: 57- 65.

12. Mabie W.C. and Sibai B.M: Hypertensive states of pregnancy, 1994; 380- 381.

13. Fernando Anias, M.O. Ph.D. Editor, practical guide to high-risk pregnancy and delivery, 2nd edition. P - 189.

14. Edited by D. Kieth Edmonds. Dewhurst's textbook of obstetrics and Gynaecology for postgraduates, 6n edition, P-172.

15. S.W. Lindow, D.A. Davey. The variability of urinary protein and creatinine excretion in patients with gestational proteinuric hypertension. Br. J Obstet Gynecol 1992; 99: PP 869-872.

16. Brodows R.G, Nichols D, Shaker G, Kubasik N: Evolution of a new radioimmunoassay for urinary albumin. Diabetes care 1986; 9: 189-93.

17. Cook J, Daneman D: Overnight VS. 24 hour urine collection in detection of microalbuminuria. Diabetes care 1990; 13: 813 .

18. Sochette E. Daneman D: Screening tests to detect microalbuminuria in children with diabetes, $\mathrm{J}$ pediatr 1988; 112:744-48.

19. Doumen CE, Van der post JA, Van Acker BA, Boer K, Koopman MG. Circadian variation of urinary albumin excretion in pregnancy. Br J obstet Gynecol 1995; 102(2): 107-110.

20. Helle Kieler, Tuttan Zettergnen, Hanna Svensson, Paul W.Diekman, Andress Larsson.Assessing urinary albumin excretion in pre-eclamptic women: Which simple to use? BJOG, 2003; 110: PP 12-17.

21. Davidson's principles and practice of medicine. Seventeenth edition 1995; P-621.

22. KUO. S.V. RN, RM, Koumantakis G and Gallery E, D.M: Proteinuria and its assessment in normal and hypertensive pregnancy. American J. Obst. Gynaecol, 1992; 167, No. 3,723-728.

23. Risberg A, Larsson A, Olssonk, Lyrenas S, Sjoquist M: Relationship between urinary albumin and albumin/creatinine ratio during normal pregnancy and pre-eclampsia. Scand JClin Lab invest. 2004; 64: 17-23. 